\title{
Trefftz method for solving two-dimensional temperature field of boiling fluid flowing along the minichannel
}

\author{
S.Hożejowska ${ }^{1}$, M.Piasecka $^{2}$, and L.Hożejowski ${ }^{3}$ \\ ${ }^{1}$ Kielce University of Technology, Chair of Mathematics, Al. 1000-lecia PP 7, 25-314 Kielce, Poland \\ ${ }^{2}$ Kielce University of Technology, Chair of Mechanics, Al. 1000-lecia PP 7, 25-314 Kielce, Poland \\ ${ }^{3}$ Kielce University of Technology, Chair of Mathematics, Al. 1000-lecia PP 7, 25-314 Kielce, Poland
}

\begin{abstract}
The paper focuses on the numerical solution to two-dimensional temperature field of boiling liquid flowing along a vertical, asymmetrically heated minichannel with a rectangular cross-section. One of the walls of a minichannel is a DC supplied heating foil. The parallel walls are made of glass panes for thermal insulation and for observation of the fluid flow and the void fraction. A thin layer of thermosensitive liquid crystal paint on the outer side of the heating foil enabled to record two-dimensional temperature distribution of outer foil surface. The paper presents computations based on Trefftz method for finding two-dimensional temperature field of boiling liquid flowing along the minichannel. The presented research is limited only to a liquid phase of the two-phase mixture observed in the minichannel. The velocity of liquid flowing through the minichannel is represented by a piecewise linear approximating function. To solve energy equation for liquid phase, Trefftz functions specially generated for this purpose were employed. Temperature field in the fluid was approximated by a linear combination of Trefftz functions. Temperature at the interface between working fluid and foil amounts to the saturation temperature. Temperature distribution in the foil and the glass pane was also computed using proper Trefftz functions.
\end{abstract}

\section{Experimental research}

\subsection{Experimental stand}

The area of interest is the issue of heat transfer into cooling liquid flowing through a rectangular minichannel with one uniformly heated enhanced wall. Experimental investigations focused on forced convection and particular attention was paid to boiling incipience conditions.

The main loop consists of the following elements: the test section with the minichannel, a rotary pump, a compensating tank (pressure regulator), a heat exchanger, a filter, rotameters and a deaerator. The essential part of the experimental stand is the test section with a minichannel (\#1), figure 1 . It is $1 \mathrm{~mm}$ deep, $40 \mathrm{~mm}$ wide and $360 \mathrm{~mm}$ long, oriented vertically. The heating element for the working fluid (FC-72) flowing along the minichannel is an alloy foil (\#2) stretched between the front cover (\#6) and the channel body (\#5). This thin foil (approx. $0.1 \mathrm{~mm}$ ) designated as Haynes-230 constitutes one of the minichannel surfaces of the rectangular section. The foil is enhanced on the side of the fluid flowing in the minichannel. The foil is energized by copper elements (\#9) with direct current of controlled intensity. It is possible to observe both surfaces of the minichannel through two openings covered with glass panes. One pane (\#4a) allows observing changes in the temperature of the foil surface. It is a plain side of the heating foil (between the foil and the glass) and is covered with thermosensitive liquid crystal paint (\#3). The opposite surface of the minichannel (from the enhanced side of the heating foil) can be observed through the other glass plane (\#4b), which helps recognize the vapour-liquid two-phase flow patterns. K-type thermocouples (\#7) are installed in the inlet and outlet of the minichannel; two pressure converters are also located in the inlet and outlet. The data from the experiment and image acquisition system include: \#10Canon Eos 550D digital SLR camera, \#11-Canon G11 digital camera, \#14-two $1 \mathrm{~kW}$ halogen reflectors with forced air cooling and heat resistant casing and \#15fluorescent and LED lamps emitting "cool white light". Experimental data have been recorded with DaqBoard 2005 data acquisition station (\#12) equipped with DASYLab software installed on a laptop (\#13). The 
heating surface in the minichannel is provided with electric current by an inverter welder (\#16) as current regulated DC power supply (up to 300 A). Regulation and control of the system are provided by: \#17-a shunt, \#18-an ammeter and \#19-a voltmeter. On one side of this foil, i.e. contacting the fluid in the minichannel, laser surface texturing was applied to obtain micro-recesses distributed in the selected area of the foil $(40 \mathrm{~mm} \times 40 \mathrm{~mm})$, as shown in figure $2 \mathrm{a}$. The microrecesses were performed by laser drilling with the diode pumped Nd:YAG laser producing UV radiation of the wavelength of $355 \mathrm{~nm}$. The recesses are distributed evenly every $100 \mu \mathrm{m}$ in both axes. They are $30 \mu \mathrm{m}$ in diameter and $5 \mu \mathrm{m}$ deep. A 1-2 $\mu \mathrm{m}$ high layer of melted metal accumulates annularly around the recesses forming the structure of "craters". The total height of the microrecesses is about $6 \mu \mathrm{m}$. The photograph of the plain and enhanced foil is shown in figure $2 b-d$.

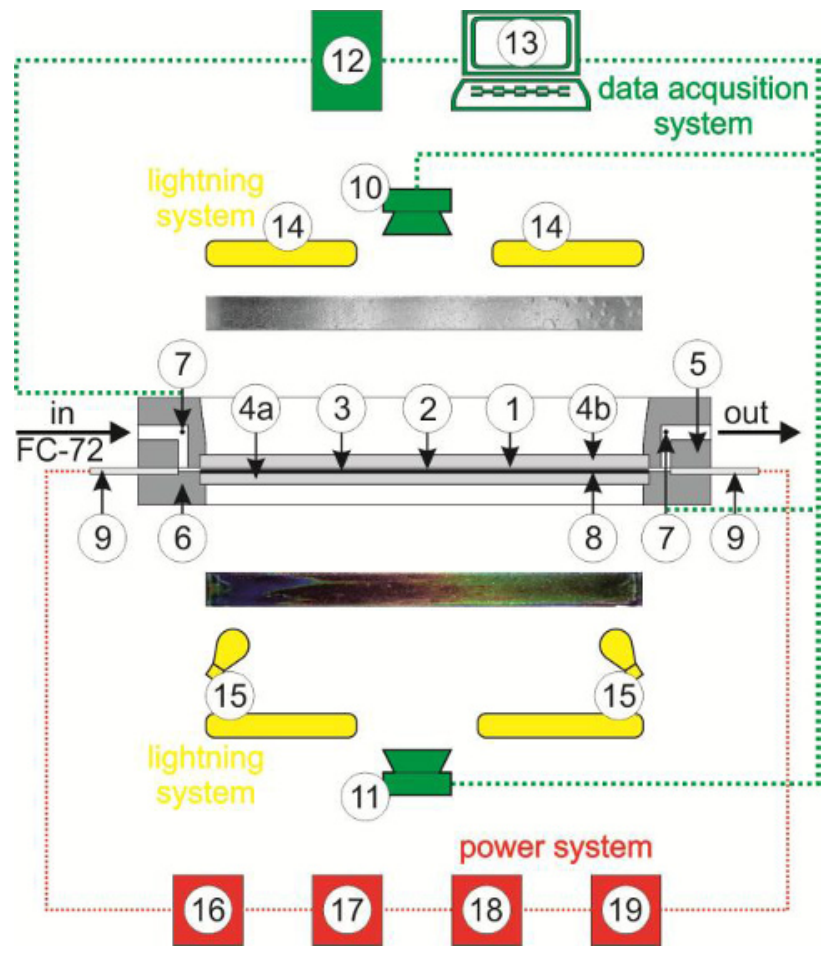

Fig. 1. The schematic diagrams of the most elements of the experimental stand: \#1-minichannel, \#2-heating foil, \#3-liquid crystal layer, \#4a,b-glass pane, \#5-channel body, \#6-front cover, \#7-thermocouple, \#8-enhanced side of the foil, \#9-copper element \#10-digital SLR camera, \#11-digital camera, \#12-data acquisition station, \#13-a laptop, \#14-halogen reflectors, \#15-fluorescent and LED lamps, \#16-inverter welder, \#17-shunt, \#18-ammeter, \#19-voltmeter.

\subsection{Experimental methodology}

Application of liquid crystals for the detection of twodimensional heating surface temperature distribution must be preceded by colour (hue) temperature calibration $[1,2]$. Evaluation of the accuracy of heating foil temperature measurements with liquid crystal thermography was discussed in [1]. Mean temperature measurement error of heating foil by liquid crystal thermography equal to $0.86 \mathrm{~K}$ was obtained. a)

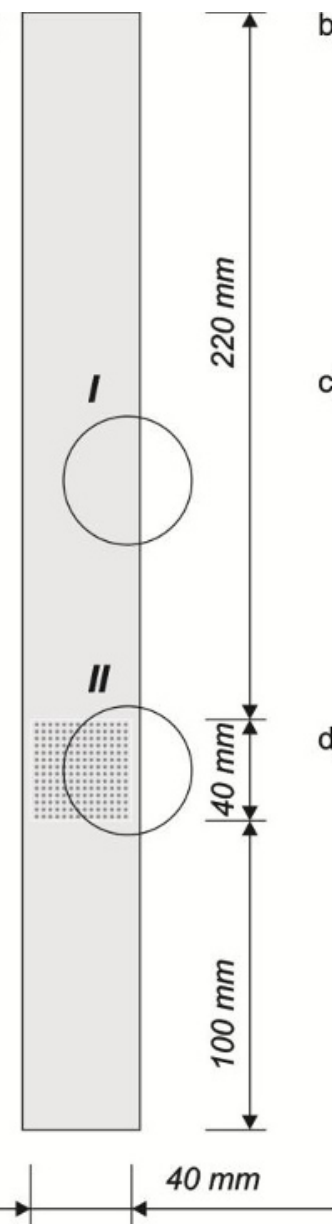

b)

c)

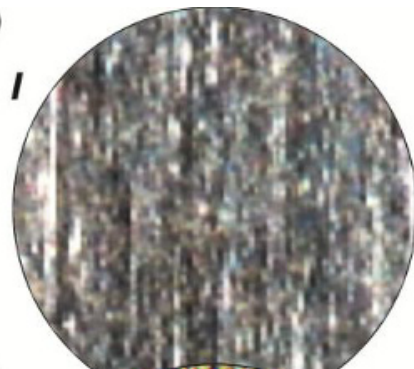

d)

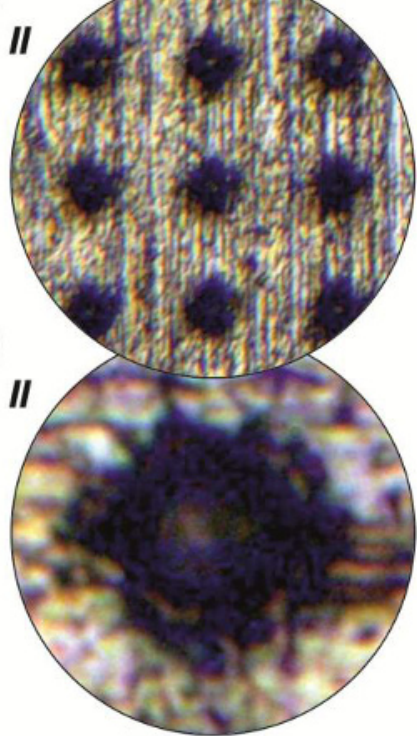

Fig. 2. a) Heating foil with the selected enhanced area; b-d) photos of the foil: plain (b), enhanced (c,d), including the photo of the single micro-recess $(\mathrm{d})$.

After deaeration, there is a laminar flow of FC-72 working fluid in the main loop in the experimental set-up. The liquid, at the temperature below its boiling point, flows laminarly into the minichannel (\#1), figure 1 . When the desired pressure and flow rate are reached, the gradual increase in the electric power supplied to the heating foil results in an increased heat flux transferred to the liquid in the minichannel. The current supplied via copper elements (\#9) to the heating foil (\#2) is controlled by an electrical system equipped with an inverter welder (\#16). This leads to the incipience and next to the development of nucleate boiling. Then, the current supplied to the foil is reduced gradually. Thanks to the liquid crystal layer located on its surface contacting the glass it is possible to measure the temperature distribution on the heating wall. Flow structure observation is carried out simultaneously at the opposite side of the minichannel.

The liquid crystal colour images of the heating foil are presented in figure 3 . When the current supplied to the heating foil increases gradually (images from \#1 up to \#19), it causes the occurrence of incipience of boiling. The "boiling front" is recognizable as the hue sequence pattern, which indicates a gradual hue changes to the liquid crystals and then sharp hue changes in the liquid crystal layer. Out-of-sensitivity-range temperatures are shown in black. This phenomenon of the occurrence of 
nucleation hysteresis was discussed in [1-4]. When the heat flux continues to increase, a new hue sequence in the upper part of images appears (from \#5 onwards). This occurs when developed nucleate boiling is in progress in the minichannel. Then the current supplied to the foil is gradually reduced (images from \#20 up to \#29). Mild hue changes, in the direction opposite to the spectrum sequence, are observed to accompany the decrease of current supplied to the foil. As a result, heat transfer returns to forced single phase convection.

\section{Void fraction determination}

\subsection{Visualisation of two phase flow structures}

The analyses of flow structure concern the minichannel with foil enhanced on the selected area. It was based on the monochrome images of flow structures with an SLR camera of heating foil, obtained on the side contacting fluid flowing in a minichannel. They were processed using Corel graphics software. After the photos had been binarized, which helped determine the boundary between the liquid and the vapour, the analysis of phase volumes was developed using special software. Techsystem Globe, analytical software, has been used in stereological analyses of digital images for quantitative assessment. The software allowed the determination of the areas of the two phases and/or percentage of the defined phase. In evaluation, the absolute error of the void fraction was assumed to be equal to the area (point) comprising $0.0064 \mathrm{~mm}^{2}$; it results from the resolution of the image taken by a digital camera.

\subsection{Void fraction determination methodology}

Three selected settings: \#2, \#7 and \#12 (see figure 3 ) for increasing of heat flux supplied to the heating surface of the foil were selected for analysis. Cross-sections of colour images are presented as (a) in figure 4 and flow structure images are shown as (b) in this figure. Four cross-sections of selected images (size of $5 \times 40 \mathrm{~mm}$ ), placed at the distance of $90 \mathrm{~mm}$ (I), $133 \mathrm{~mm}$ (II), $270 \mathrm{~mm}$ (III) and $336 \mathrm{~mm}$ (IV) from the inlet to the minichannel were selected. The binarized images of two-phase flow structure images (black and white) adapted for analysis in Techsystem Globe are presented as (c) in the figure 4.The void fraction was determined according to the following formula $[1,3]$ :

$$
\varphi=\frac{V_{\mathrm{v}}}{V_{\mathrm{L}}+V_{\mathrm{v}}}=\frac{A_{\mathrm{v}} \cdot \delta_{\mathrm{M}}}{\left(A_{\mathrm{L}}+A_{\mathrm{v}}\right) \cdot \delta_{\mathrm{M}}}=\frac{A_{\mathrm{v}}}{A_{\mathrm{L}}+A_{\mathrm{v}}}
$$

where: $V$-volume, $A$-cross section area, $\delta$-depth. In our notation, the subscripts referring to the glass pane, the heating foil, the liquid, the vapour and the minichannel are denoted with letters: $G, F, L, v$ and $M$, respectively. Liquid and vapour cross-section areas were obtained from phase image analysis performed by means of Techsystems Globe software. The results are presented in the figure 5 as void fraction dependence along the minichannel length for settings \#2, \#7 and \#12.

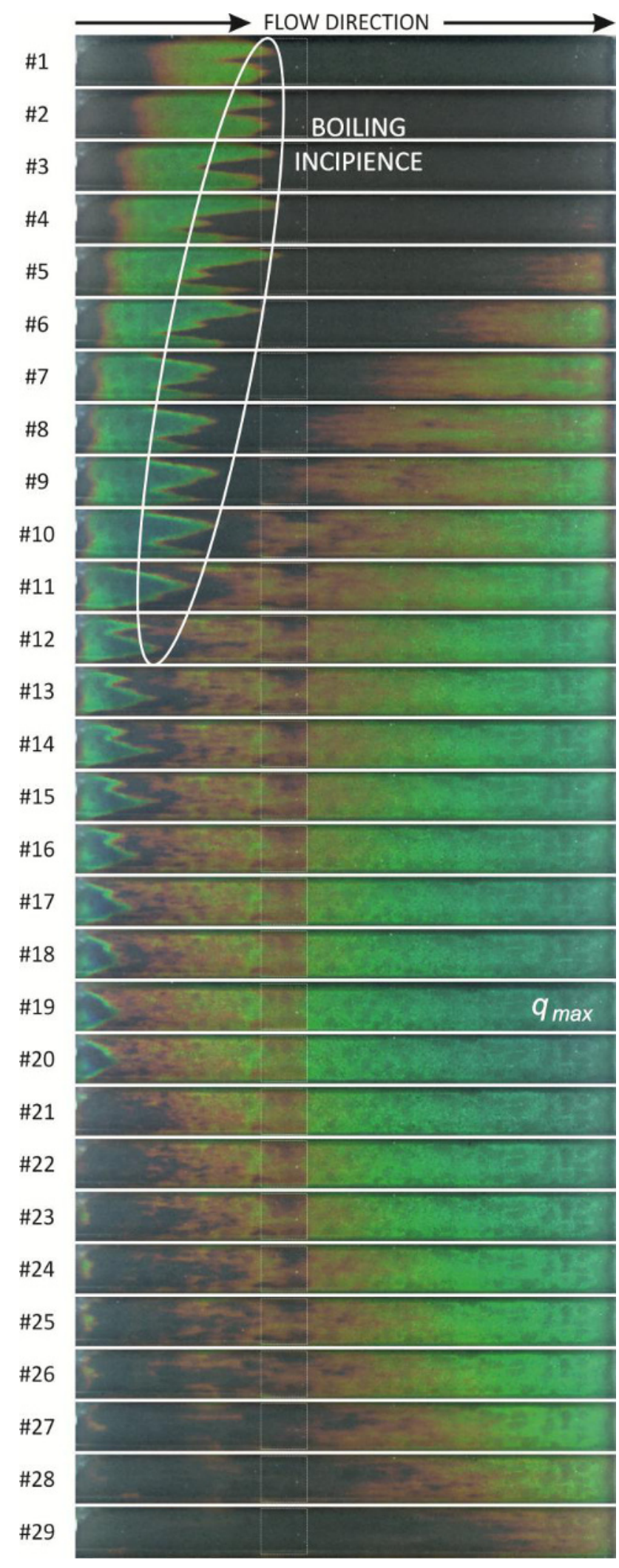

Fig. 3. Colour heating foil images while increasing and later decreasing heat flux supplied to the foil, experimental parameters: flow velocity $0.14 \mathrm{~m} \mathrm{~s}^{-1}$, mass flux $235 \mathrm{~kg} \mathrm{~m}^{-2} \mathrm{~s}^{-1}$, Reynolds number $R e=750$, inlet pressure $135 \mathrm{kPa}$, inlet liquid subcooling $45 \mathrm{~K}$,

volumetric heat flux $1.06 \cdot 10^{5} \div 2.76 \cdot 10^{5} \mathrm{~kW} \mathrm{~m}^{-3}$, heat flux density $10.79 \div 28.06 \mathrm{~kW} \mathrm{~m}^{-2}, q$ - heat flux. 


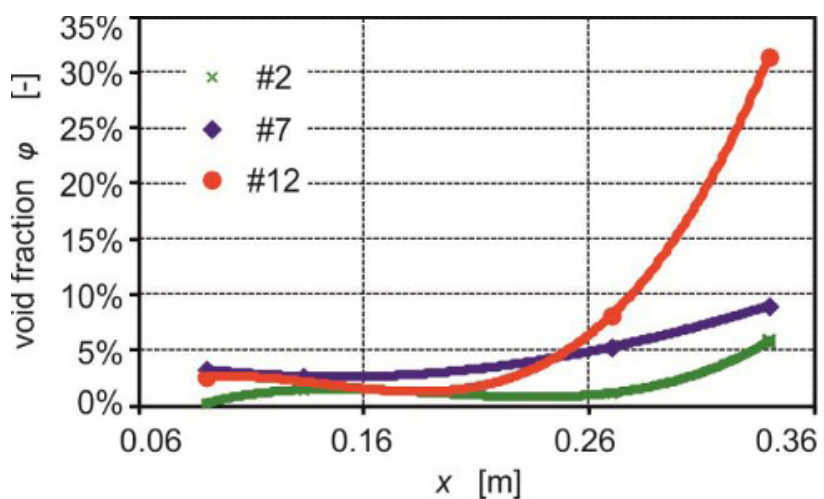

Fig. 5. Void fraction dependence along the minichannel length for selected cross sections for settings: \#2, \#7, \#12, parameters as for figure 3 .

\section{Mathematical model}

\subsection{Problem formulation}

In mathematical model the investigations took into account the dimension along the flow direction $(x)$, but the dimension perpendicular to it $(y)$ was related to the test section composed of the glass pane, heating foil and minichannel with cooling liquid. Further considerations are focused on the central part of the minichannel (along its length) so that the physical phenomena occurring on outer sides of the minichannel have no influence on thermodynamical parameters in the region under consideration.

Subcooling liquid at a temperature lower than saturation temperature enters the minichannel and it is heated by the heating foil during its flow. We assume both for stationary and laminar flow $(R e=750)$ that velocity vector is parallel to the axis of the minichannel so it has only one non-zero component $u=u(y)$. The component $u(y)$ is approximated by a following roof function

$$
u(y)=u_{\max }\left(1-\delta_{\mathrm{M}}\left|2 y-\delta_{\mathrm{M}}\right|\right)
$$

where $u_{\max }$ is equal to the doubled average velocity. The incipience of boiling can be modelled by the energy equation and, provided the equation is valid for liquid phase only, it has the following form

$$
\frac{\partial^{2} T_{\mathrm{L}}}{\partial x^{2}}+\frac{\partial^{2} T_{\mathrm{L}}}{\partial y^{2}}=\frac{c_{\mathrm{L}} \rho_{\mathrm{L}}}{\lambda_{\mathrm{L}}} u(y) \frac{\partial T_{\mathrm{L}}}{\partial x}
$$

where: $c_{\mathrm{L}}-$ specific heat, $\rho_{\mathrm{L}}$ - density, $\lambda_{\mathrm{L}}$ - thermal conductivity.

The following boundary conditions were specified for the equation (3):

- temperature of the liquid in the inlet and outlet of the minichannel equals $T_{\text {in }}$ and $T_{\text {out }}$, respectively, i.e.

$$
\begin{aligned}
& T_{\mathrm{L}}(0, y)=T_{\text {in }} \text { for } 0 \leq y \leq \delta_{M} \\
& T_{\mathrm{L}}(L, y)=T_{\text {out }} \text { for } 0 \leq y \leq \delta_{M}
\end{aligned}
$$

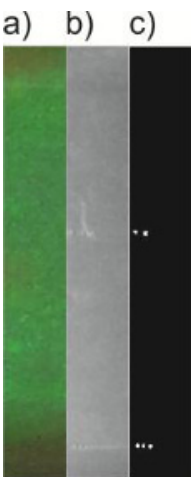

\#2-I

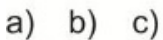

\#7-I
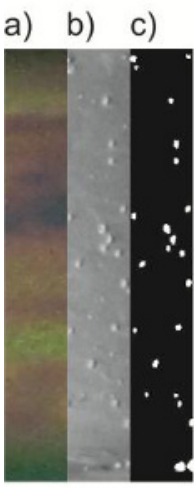

\#12-I

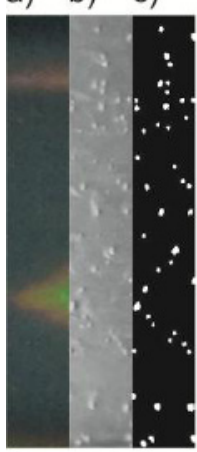

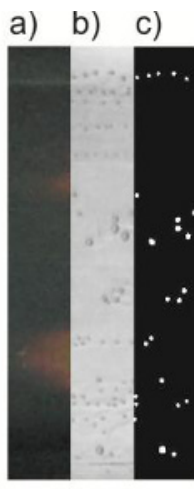

\#2-II

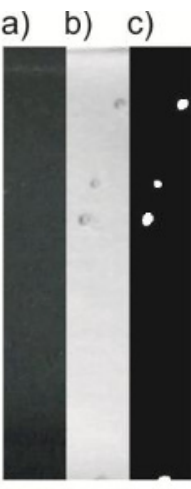

\#2-III

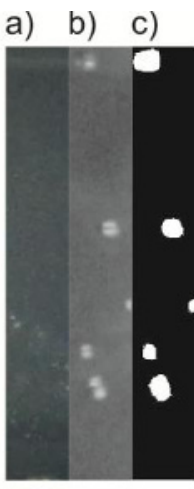

\#2-IV

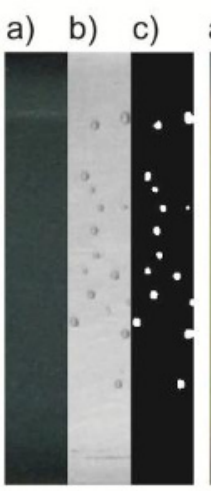

\#7-II

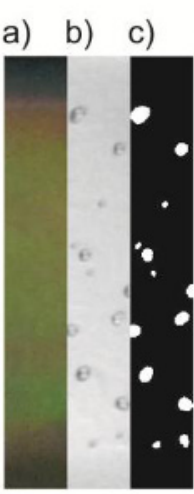

\#7-III

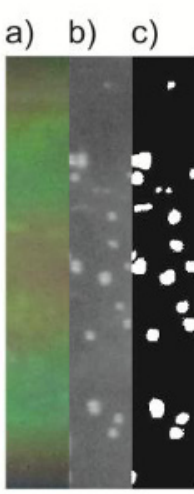

\#7-IV
Fig. 4. Selected images for settings: \#2, \#7 and \#12: colour image (a), real (b) and binarized (c) two-phase flow structure images; white colour refers to the vapour, and the black colour represents the liquid.

- temperatures of the liquid and the foil at the interface are equal:

$$
\begin{gathered}
T_{\mathrm{L}}(x, 0)=\left\{\begin{array}{c}
T_{\mathrm{F}}(x, 0), \quad \text { if } \quad T_{\mathrm{F}}(x, 0)<T_{\text {sat }}(x) \\
T_{\text {sat }}(x), \quad \text { if } \quad T_{\mathrm{F}}(x, 0) \geq T_{\text {sat }}(x)
\end{array}\right. \\
\text { for } 0 \leq x \leq L
\end{gathered}
$$

where: $T_{\text {sat }}$ - varies linearly with pressure in the minichannel;

- the two-phase mixture per unit volume in minichannel contains vapor phase and liquid phase in proportion $\varphi$ and $(1-\varphi)$, respectively. We assumed that the same proportion of vapor and liquid phases refers to any crosssectional area of the minichannel and then to the heat exchange surface $[5,6]$. Hence, all heat generated by the 
heating foil is transferred to liquid phase proportionally to the void fraction:

$\lambda_{\mathrm{L}} \frac{\partial T_{\mathrm{L}}}{\partial y}=\lambda_{\mathrm{F}}(1-\varphi(x)) \frac{\partial T_{\mathrm{F}}}{\partial y}$ for $y=0$ and $0 \leq x \leq L$

Stationary heat transfer in the glass pane and heating foil can be described by the following differential equations:
(a) for glass $\Delta T_{\mathrm{G}}=0$
(b) for foil $\Delta T_{\mathrm{F}}=-\frac{q_{\mathrm{V}}}{\lambda_{\mathrm{F}}}$

where $q_{\mathrm{V}}$ means volumetric heat flux. For these equations we assume continuity of temperature and heat flux at the foil-glass interface:

$$
\begin{gathered}
T_{\mathrm{F}}\left(x_{\mathrm{k}},-\delta_{\mathrm{F}}\right)=T_{\mathrm{G}}\left(x_{\mathrm{k}},-\delta_{\mathrm{F}}\right)=T_{\mathrm{k}} \\
\lambda_{\mathrm{F}} \frac{\partial T_{\mathrm{F}}}{\partial y}=\lambda_{\mathrm{G}} \frac{\partial T_{\mathrm{G}}}{\partial y} \text { for } y=-\delta_{\mathrm{F}} \text { and } 0 \leq x \leq L
\end{gathered}
$$

where $T_{\mathrm{k}}$ means the measurements obtained with liquid crystal thermography at the foil-glass contact at discrete points $\left(x_{\mathrm{k}},-\delta_{\mathrm{F}}\right)$. To complete specification of the functions $T_{\mathrm{F}}$ and $T_{\mathrm{G}}$ we assume that the outer surfaces of the minichannel are thermally isolated. Figure 6 contains the geometry and prescribed conditions of the considered problem.

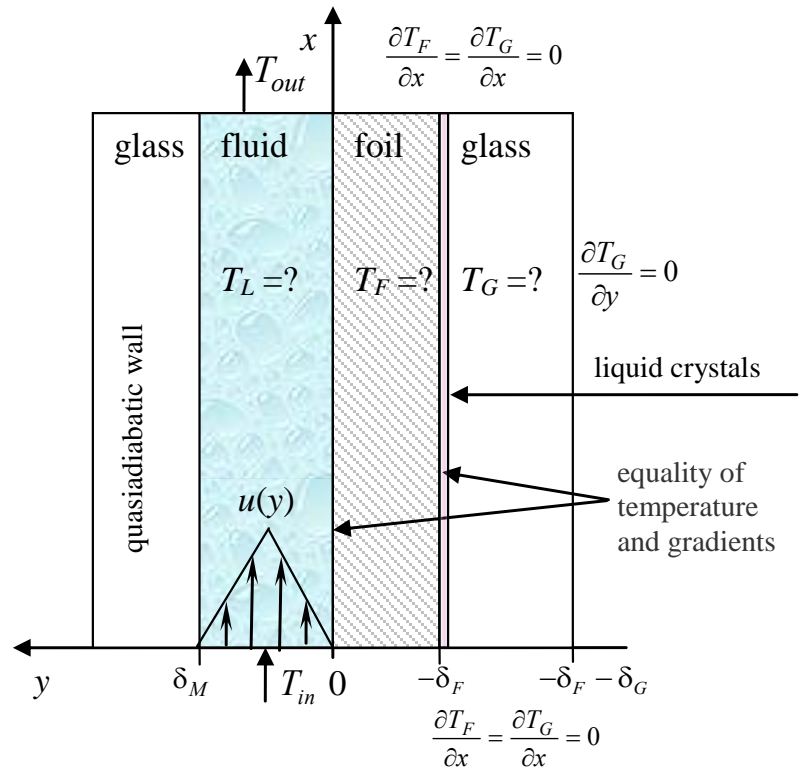

Fig. 6. Diagram of the boiling liquid flow in the minichannel, with the adapted boundary conditions; (pictorial view, not to scale).

\subsection{Trefftz method}

Eq. (3) subject to prescribed boundary conditions (4)-(7) will be solved by the Trefftz method. In this method the unknown solution of a differential equation is approximated with a linear combination of the functions (so called Trefftz functions) which satisfy the governing equation. The unknown coefficients are determined by matching the boundary conditions. Before numerical calculations we have to generate Trefftz functions corresponding to Eq. (3) with roof-shaped velocity of the liquid, $u(y)$. The unknown solution to Eq. (3) is expanded in Taylor series, around the point $(0,0)$ :

$$
\begin{aligned}
& T_{\mathrm{L}}(x, y)=T_{\mathrm{L}}(0,0)+\frac{\partial T_{\mathrm{L}}}{\partial x} x+\frac{\partial T_{\mathrm{L}}}{\partial y} y+\frac{1}{2 !} \frac{\partial^{2} T_{\mathrm{L}}}{\partial x^{2}} x^{2}+ \\
& +\frac{2}{2 !} \frac{\partial^{2} T_{\mathrm{L}}}{\partial x \partial y} x y+\frac{1}{2 !} \frac{\partial^{2} T_{\mathrm{L}}}{\partial y^{2}} y^{2}+\frac{1}{3 !} \frac{\partial^{3} T_{\mathrm{L}}}{\partial x^{3}} x^{3}+\ldots
\end{aligned}
$$

From Eq. (3) we get the dependence concerning the second partial derivative $\frac{\partial^{2} T_{\mathrm{L}}}{\partial y^{2}}$

$$
\frac{\partial^{2} T_{\mathrm{L}}}{\partial y^{2}}=\frac{c_{\mathrm{L}} \rho_{\mathrm{L}}}{\lambda_{\mathrm{L}}} u(y) \frac{\partial T_{\mathrm{L}}}{\partial x}-\frac{\partial^{2} T_{\mathrm{L}}}{\partial x^{2}}
$$

which we substitute into Eq. (11) and after some algebraic manipulations the unknown solution $T_{L}$ has the following representation

$$
T_{\mathrm{L}}(x, y)=\sum_{n=1}^{\infty} b_{\mathrm{n}} v_{\mathrm{n}}(x, y)
$$

where polynomials $v_{\mathrm{n}}(x, y)$ are the desired Trefftz functions satisfying the energy equation (3) identically. Next, we approximate the solution $T_{\mathrm{L}}$ with finitely many $v_{\mathrm{n}}(x, y)$ 's which gives

$$
T_{\mathrm{L}}(x, y) \approx \sum_{n=1}^{N} b_{\mathrm{n}} v_{\mathrm{n}}(x, y)
$$

The unknown coefficients of this expansion, $b_{\mathrm{n}}$, will be selected to make the approximant $T_{\mathrm{L}}$ best match (in variational sense) the boundary conditions (4)-(7). In terms of computations, by proper choice of $b_{\mathrm{n}}$ 's one should minimize the functional $J$ that describes mean square error between approximated and prescribed values of temperature or heat flux on the boundaries of the considered domain. The functional has the following form

$$
\begin{aligned}
J & =\int_{0}^{\delta_{\mathrm{M}}}\left(\sum_{n=1}^{N} b_{\mathrm{n}} v_{\mathrm{n}}(0, y)-T_{\mathrm{in}}\right)^{2} d y+\int_{0}^{\delta_{\mathrm{M}}}\left(\sum_{n=1}^{N} b_{\mathrm{n}} v_{\mathrm{n}}(L, y)-T_{\text {out }}\right)^{2} d y+ \\
& +\int_{0}^{L}\left(\sum_{n=1}^{N} \lambda_{\mathrm{L}} b_{\mathrm{n}} \frac{\partial v_{\mathrm{n}}(x, 0)}{\partial y}-\lambda_{\mathrm{F}}(1-\varphi(x)) \frac{\partial T_{\mathrm{F}}(x, 0)}{\partial y}\right)^{2} d x+ \\
& +\int_{0}^{L}\left(\sum_{n=1}^{N} b_{\mathrm{n}} v_{\mathrm{n}}(x, 0)-T_{\text {sat }}(x)\right)^{2} d x
\end{aligned}
$$

Finally we get the solution $T_{\mathrm{L}}$ which satisfies the energy equation (3) exactly and the boundary conditions approximately. In the like manner we can obtain the solutions of Eqs. (8a) and (8b) using Trefftz functions (harmonic polynomials) suitable for Laplace equation [4]. Trefftz method allows to determine two-dimensional 
distributions of temperature in the foil and in the glass as well as their gradients along the minichannel.

\section{Results}

Numerical calculations were performed for experimental data and they concerned forced flow of the cooling liquid FC-72 through asymmetrically heated vertical minichannel. Our considerations focused only on the incipience of the nucleate boiling, see figure $7 \mathrm{a}$. Calculations were conducted for setting \#2, with all parameters of the experiment given in figure 3 . The void fraction described in detail in 2.2. was approximated with a third degree polynomial as shown in figure $7 \mathrm{~b}$.

a)

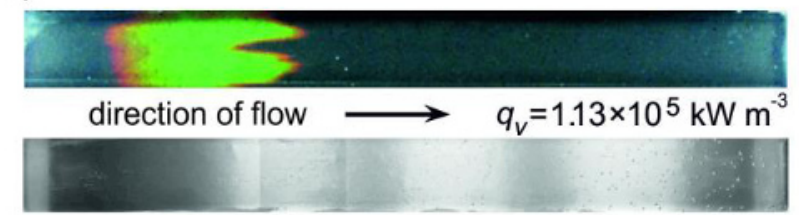

b)

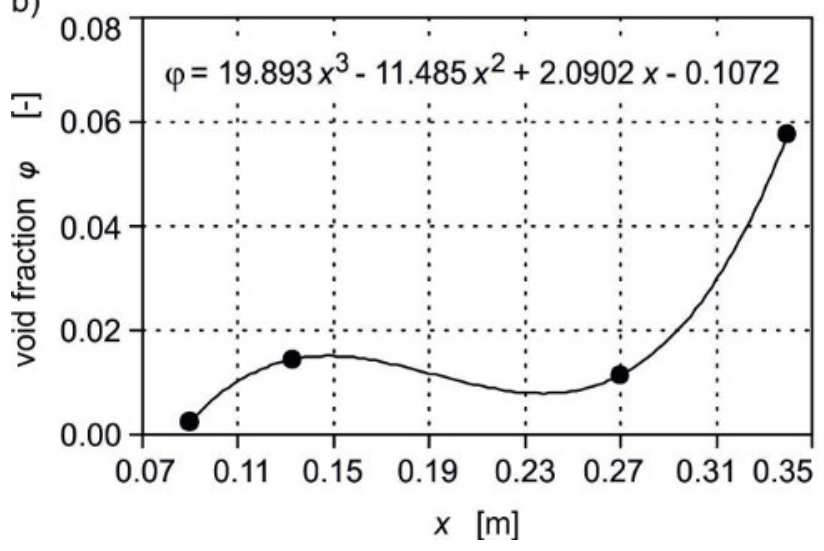

Fig. 7. a) Hue distribution at the foil-glass interface obtained with liquid crystal thermography and observed flow structure

for the given temperature distribution, b) void fraction dependence along the minichannel length for selected. Setting \#2.

The first stage of computations involved the use of Trefftz method for finding two-dimensional temperature distribution in the glass pane and the heating foil. In the next step temperatures were calculated in the liquid phase. We designed approximate temperature distributions $T_{\mathrm{G}}, T_{\mathrm{F}}, T_{\mathrm{L}}$ to be polynomials of the same degree. Figure 8a presents two-dimensional temperature distribution in the heating foil and the glass pane, both obtained by Trefftz method. Either of the approximants satisfies the assumed conditions (9) and (10), with a relatively high accuracy. Similarly, figure 9 a shows temperature field in the heating foil and the flowing liquid. One can notice the characteristic shape of isotherms in the liquid (see figure 9a) which is due to modelling the velocity vector as a roof function. In figure $9 \mathrm{~b}$ temperatures of the heating foil and the liquid at the foil-liquid interface are compared to saturation temperature. In [5] similar research, assuming a parabolic fluid velocity profile, was conducted for bubbly and bubbly-slug flow.
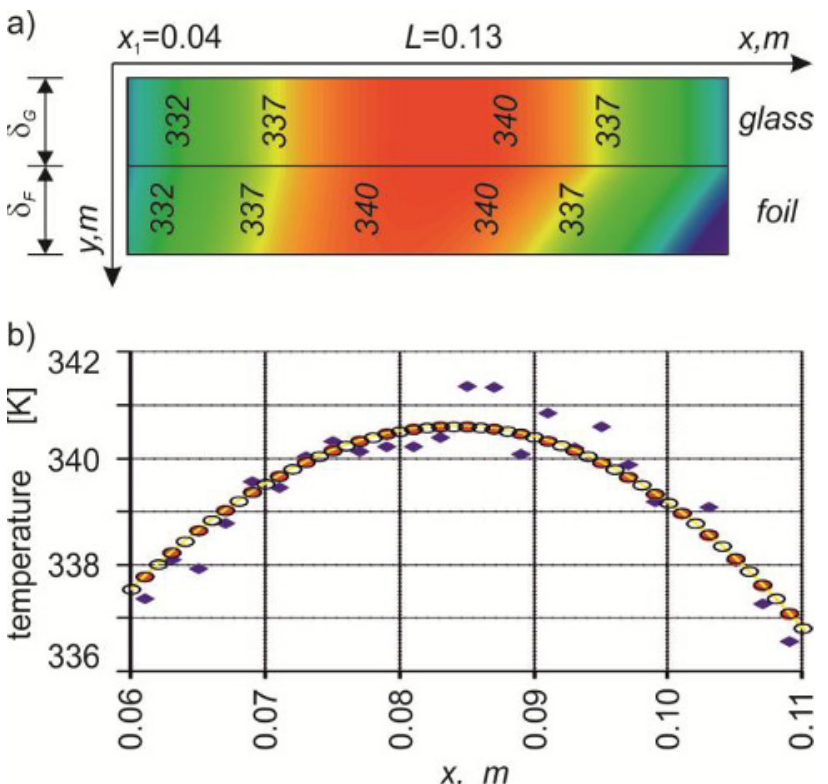

Fig. 8. a) Two dimension temperature distributions of the glass pane and the heating foil, both obtained with Trefftz method,

b) temperatures of the measurements (blue $\diamond$ ), glass pane (white o) and foil (red $\bullet$ ) at the glass-foil contact. Setting \#2.

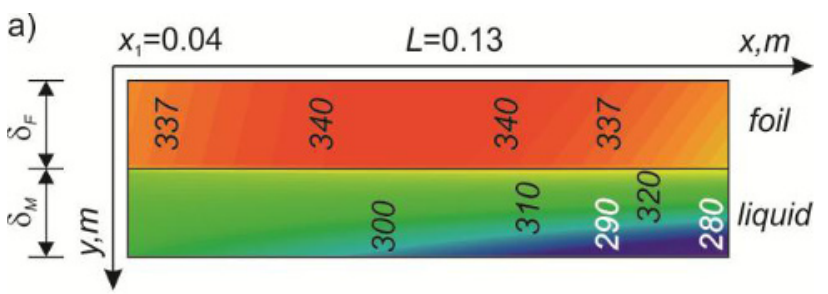

b)

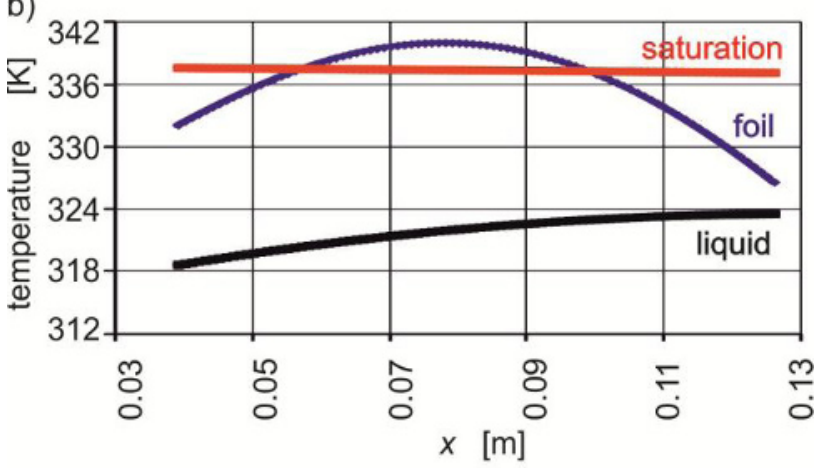

c)

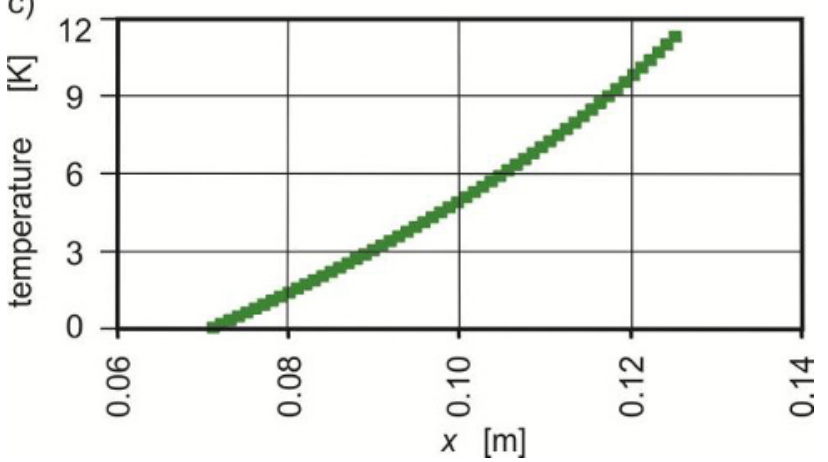

Fig. 9. a) Two dimension temperature distributions of the heating foil and of the liquid, both obtained with Trefftz method, b) temperatures of the foil (blue), of the liquid (black) and saturation (red) at the foil-liquid contact as a function of distance from the inlet to the channel; c) heat transfer coefficient as a function of distance from the inlet to the channel. Setting \#2. 
The known liquid and foil temperature distributions allowed calculating heat transfer coefficient $\alpha$ at the foilglass contact points from the convective boundary condition

$$
-\lambda_{\mathrm{F}} \frac{\partial T_{\mathrm{F}}(x, 0)}{\partial y}=\alpha(x)\left(T_{\mathrm{F}}(x, 0)-T_{\mathrm{ave}}(x)\right)
$$

where average temperature of the liquid $T_{\text {ave }}(x)=\frac{1}{\delta_{\mathrm{M}}} \int_{0}^{\delta_{\mathrm{M}}} T_{\mathrm{L}}(x, y) d y$, was assumed to be the reference temperature.

In the minichannel flow boiling, considerable heat transfer enhancement takes place at boiling incipience. It is observed as a sharp increase in the heat transfer coefficient at the foil-liquid contact, see figure 9c.

\section{Conclusions}

The present paper presents the first approach to modelling laminar flow of the fluid during incipience of nucleate boiling.

After we had set up a mathematical model of the problem, we used Trefftz method to solve it, however the validity of our solution is restricted to liquid phase only. Special Trefftz functions had to be generated for the case of roof-shaped velocity of the liquid.

The chosen method based on Trefftz functions was successfully applied to the direct problem of finding temperature distribution in the glass pane. Moreover, this method turned to be suitable for the considered inverse problems: in the heating foil were we had a specified condition at one boundary and in the liquid where we assumed convective boundary condition in order to compute the heat transfer coefficient. The obtained numerical results show high compliance with physical assumptions of the model and have satisfactory accuracy.

Since the results based on Trefftz method turned to be promising, further research will be devoted to adapting the method to finding temperature distribution in the fluid which would include vapor phase as well as liquid phase.

\section{Acknowledgements}

The research has been financed by the Polish Ministry of Science and Higher Education, Grant No. N N512 354037 for the years 2009-2012.

\section{References}

1. M. Piasecka, B. Maciejewska, Exp. Therm. Fluid Sci. 38 (2012)

2. S. Hozejowska, M. Piasecka, M.E. Poniewski, Int. J. Therm. Sc. 48, 6 (2009)

3. M. Piasecka, Proc. ECI $8^{\text {th }}$ Int. Conf. on Boiling and Condensation Heat Transfer, 3-7.06.2012, Lausanne, Switzerland (2012)
4. M. Piasecka, S. Hozejowska, M.E. Poniewski, Int.J. Heat and Fluid Flow, 25 (2004)

5. S.Hozejowska, M.E. Poniewski, Proc. CPOTE $3^{\text {th }}$, Int.Conf. on Contemporary Problems of Thermal Engineering, 18-20 09 2012, Gliwice, Poland (2012)

6. T.Bohdal, Arch. of Therm., 21 (2000) 